\title{
Quality of Canadian commercial plain non-fat Greek- style yogurts produced only from natural dairy ingredients
}

\section{Ignace Lange ${ }^{1}$, Stanisław Mleko ${ }^{2}$, Marta Tomczyńska-Mleko ${ }^{2}$, Galyna Polishchuk ${ }^{3}$, Piotr Janas ${ }^{2}$, Lech Ozimek ${ }^{1}$}

1 - University of Alberta, Edmonton, Canada

2 - University of Life Sciences in Lublin, Lublin, Poland

3 - National University of Food Technologies, Kyiv, Ukraine

Keywords:

Yoghurt

Greek-style

Whey

Syneresis

Rheology

Article history:

Received

16.05.2020

Received in revised

form 28.09.2020

Accepted

27.12.2020

Corresponding

author:

Marta

Tomczyńska-Mleko

E-mail:

martamleko@tlen.pl

DOI:

$10.24263 / 2304$

974X-2020-9-4-3

\section{Abstract}

Introduction. Article presents evaluation of quality of Canadian commercial plain non-fat Greek-style yogurts produced only from natural dairy ingredients.

Material and methods. Yogurts samples were purchased 10 days after their production and were stored at $5^{\circ} \mathrm{C}$ to obtain 18 or 35 days of storage. Dynamic rheological properties and surface wheyoff were measured. An ordinal numerical scale was used in order to evaluate whey drainage and the presence and size of visible clusters.

Results and discussion. Greek-style yogurt is a typical weak viscoelastic gel whose elastic properties predominate over its viscous properties over the measured range. A structural degradation was observed in all samples at some point during the stress-amplitude range applied. B samples had a higher total solids content than A samples therefore, this might be the reason that $\mathrm{B}$ samples presented higher dynamic moduli than A samples, even for the same protein content. Both reference samples presented a significant increase in their viscous ( $\left.G^{\prime \prime}\right)$ and elastic $\left(G^{\prime}\right)$ moduli upon storage at $5^{\circ} \mathrm{C}$. This fact suggests that casein gels are dynamic by nature and that further development of the gel structure occurs during storage. At high amplitudes, A samples presented a significant increase in their $\tan \delta$ values due to the rupture of their gel structures. A proportional increase in $\mathrm{G}^{\prime}$ and $\mathrm{G}^{\prime \prime}$ during storage was observed; hence, the $\tan \delta$ values for the same types of samples, after 18 and 35 days of storage, were similar. Samples did not differ in levels of whey drainage and in the size of visible clusters. Both market samples presented higher amounts of surface whey-off as storage time increased. Probably during storage, large scale rearrangements occurred in the gel network which increased the level of instability of the gel, resulting in the loss of the ability to entrap all the serum phase. Although none of the reference samples had visible whey drainage, all of them presented small visible clusters.

Conclusions. Protein is not the only ingredient shaping structure and rheological properties of Greek-style non-fat yoghurt. Properties of commercial plain non-fat Greek-style yogurts changes at the storage time. Samples becomes more solid, but with higher whey syneresis. 


\section{Introduction}

Greek-style yogurt (strained yogurt) is a semisolid dairy product obtained by removing part of the whey from regular yogurt [1-3]. As a result of this action, the total solids content and lactic acid concentration of the initial yogurt are increased (concentrated yogurt typically contains $22-23 \mathrm{~g} / 100 \mathrm{~g}$ total solids and has an acidity of around $1.60-1.80 \mathrm{~g} / 100 \mathrm{~g}$ lactic acid), giving the final product a much thicker consistency and a distinctive, slightly tangy taste [4, 5]. In addition, the product obtained has nutritional properties superior to those of regular yogurt, with higher protein and mineral contents and very low lactose content. It also has better keeping qualities due to the increased lactic acid concentration [6-8].

Health benefits associated with yogurt cultures and probiotics led to a sharp increase in the per capita consumption of yogurt in Canada and the United States during the last decades [9]. According to Chandan [10], yogurt sales in the U.S. have been spectacular, increasing from 1,837 million pounds in the year 2000 to 2,990 million pounds in 2005 , and they continue to show remarkable growth. Overall yogurt category sales increased $12 \%$ year after year. Of those sales, $85 \%$ was driven by a $146 \%$ increase in Greek-style yogurt sales, while a $2 \%$ increase in traditional yogurt sales accounted for only $15 \%$ of category growth [9].

To take advantage of the current remarkable economic growth of Greek-style yogurt, the issue of good quality is very important. Some researchers work on development of an efficient formulation for the production of strained yogurt powder. It is believed that a dried type of concentrated yogurt will help to expand the economic boom of Greek-style yogurt in areas that have a limited indigenous dairy industry, or regions that suffer from seasonal deficiencies in milk supply [11]. Thus, this type of product is intended to open new markets to this highly valuable food commodity.

The pronounced economic growth of Greek-style yogurt has led to a noticeable diversification of the traditional product. Many mechanized systems based on modern techniques, such as membrane processes, centrifugation, and direct reconstitution, have been developed to manufacture strained yogurt in large volumes [1, 12-14]. Because the overall characteristics of concentrated yogurt depend on the method of production, the use of different manufacturing methods has led to the production of diverse varieties of commercial Greek-style yogurt which significantly differ in their composition [1, 15]. Tamime [16] and Tamime \& Robinson [17] have reported about the difference in composition of various types of commercial concentrated yogurt that exist around the world. In order to respond to the increasing consumer preference for reduced fat and additive-free products, the current study will emphasize the production of a non-fat, additive-free type of yogurt [18].

Regardless of the production method and composition of the final product, one of the major concerns facing the Greek-style yogurt industry is the production and maintenance of a product with optimum consistency, stability and texture properties [19]. The overall visual appearance, microstructure, and rheological properties of acid milk gels are important physical attributes which contribute to the overall sensory perception and functionality of these products [20]. Textural attributes, including the desired oral viscosity, are very important criteria for quality and for consumer acceptance of yogurt [21]. Skriver et al. [22], Richardson et al. [23], and Stanley \& Taylor [24] reported that sensory texture analyses are highly correlated with the rheological properties of stirred yogurt and other semi-solid foods. Thus, the objective of this experiment was to evaluate the quality of commercial Greek-style yogurt and its "on shelf" stability. Such stability is particularly difficult to preserve for natural non-fat yoghurts. Fat is an ingredient which stabilizes the structure and texture of yogurt and makes it more attractive for consumers. Different texture shaping ingredients added to many 
commercial yogurts enable to obtain a product with any desired texture and stability. Much more difficult it to obtain product based only on non-fat milk ingredients.

The aim of this study was to to investigate the structure and rheological properties of non-fat Greek-style yogurts with different dry matter content, produced only from natural dairy ingredients.

The research tasks:

1. To analyse the current state of production of Greek-style yogurts;

2. To investigate the quality indicators of commercial samples of non-fat Greek-style yogurts;

3. To identify patterns of changes in the structure of the protein gel of yogurt with different dry matter content during storage.

\section{Materials \& methods}

\section{Market reference samples}

All types of commercial, plain Greek-style yogurts (0\% M.F.) produced from natural dairy ingredients without added preservatives, emulsifiers or stabilizers (according to their labeling), that were commercialized in Edmonton (Canada) by three supermarket chains (Walmart, Superstore, and Safeway) were used as reference samples in this study. Two products that met these requirements were labeled as " $A$ " and " $B$ ". Reference samples were purchased 10 days after their production and were stored at $5{ }^{\circ} \mathrm{C}$ to obtain 18 or 35 days of storage. Specifications of these samples are shown in Table 1.

Specifications of the market reference samples used in this study

Table 1

\begin{tabular}{|l|c|c|}
\hline & A & B \\
\hline Ingredients $^{¥}$ & $\begin{array}{c}\text { Skim milk, live active } \\
\text { cultures }\end{array}$ & $\begin{array}{c}\text { Skim milk, live active } \\
\text { cultures }\end{array}$ \\
\hline Production method $^{\dagger}$ & Traditional/Stirred & Traditional/Stirred \\
\hline Shelf life (Days) & 35 & 35 \\
\hline Fat content $(\%)^{¥}$ & 0.0 & 0.0 \\
\hline Protein content $(\%)^{¥}$ & 10.3 & 10.3 \\
\hline $\begin{array}{l}\text { Carbohydrates content } \\
(\%)^{¥}\end{array}$ & 3.4 & 6.9 \\
\hline${\text { Total Solids content }(\%)^{\S}}^{¥}$ & 13.7 & 17.1 \\
\hline
\end{tabular}

${ }^{¥}$ Specifications obtained from products labels.

${ }^{\dagger}$ Specifications obtained from customer services.

$\S$ Total solids content was calculated based on the carbohydrates, fat and protein contents.

\section{Dynamic rheological measurements}

Small amplitude oscillatory rheology (SAOR) tests were performed with a Paar Physica UDS200 MCR Rheometer. The evaluation method was adapted from Ozer et al. [25-27]. The rheometer was set up with a parallel-plate geometry $(10 \mathrm{~mm}$ plate radius and $1 \mathrm{~mm}$ gap setting). All samples were gently stirred with a spoon for 30 seconds before measurement in order to mix the potential free whey with the resultant gel. Each sample was loaded into the rheometer and allowed to relax and equilibrate to measuring temperature $\left(25 \pm 0.1^{\circ} \mathrm{C}\right)$ for 2 
minutes prior to testing. The temperature of the samples inside the rheometer was maintained by a circulating cooling system. Rheological aspects of all samples were evaluated by conducting stress amplitude sweep tests. A sweeping amplitude from $1.5 \times 10^{-2}$ to $1.5 \times 10^{-1} \mathrm{mNm}$ at $0.25 \mathrm{~Hz}$ was used and 25 measuring points were performed through the sweeping range. Storage $\left(G^{\prime}\right)$ and loss $\left(G^{\prime \prime}\right)$ moduli were recorded. Three replications were conducted for each sample.

\section{Whey separation measurements}

Surface whey-off (SWO). The method used to quantify the amount of free whey present on top of the resultant gel was adapted from Lucey et al. [28]. Experimental samples were evaluated before and after applying homogenization during their production. Any free whey expelled on top or around the sides of the gel was gently sucked with a polyethylene transfer pipette and weighted. Once all the free whey was sucked from the surface, the gel was allowed to rest for 1 minute and any further surface whey was sucked and weighted. The degree of whey separation was expressed as a percentage of the total sample weight $(\% \mathrm{~m} / \mathrm{m})$. After quantification, free-whey was reintroduced into the samples.

Whey drainage (WD). To evaluate the degree of whey drainage present in the final samples, the resultant gels were broken with a spoon and the level of whey drainage was quantified using an ordinal numerical scale from 0 (no visible whey drainage) to 2 (high amount of whey drainage). Figure 1 illustrates the different levels that were used to classify the samples according to whey drainage.

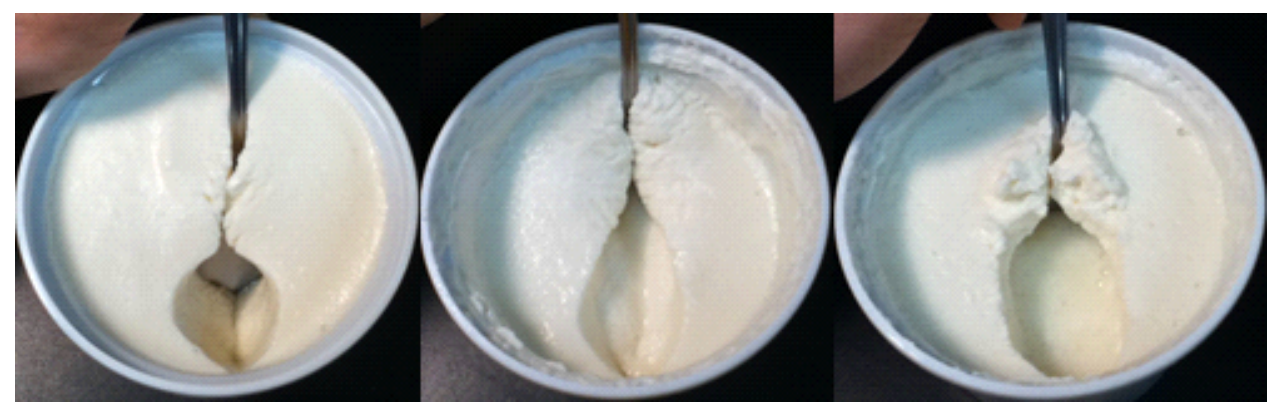

Level 0 Level 1

Level 2

Figure 1. Ordinal levels used for the classification of samples according to the degree of whey drainage

Presence and size of visible clusters. An ordinal numerical scale from 0 (no visible clusters) to 3 (big visible clusters) was used in order to evaluate the presence and size of visible clusters in the final products. All samples were gently stirred with a spoon for 30 seconds before the evaluation in order to mix the potential free whey with the resultant gel. Figure 2 shows the different levels that were used to classify the samples according to the presence and size of the clusters. 


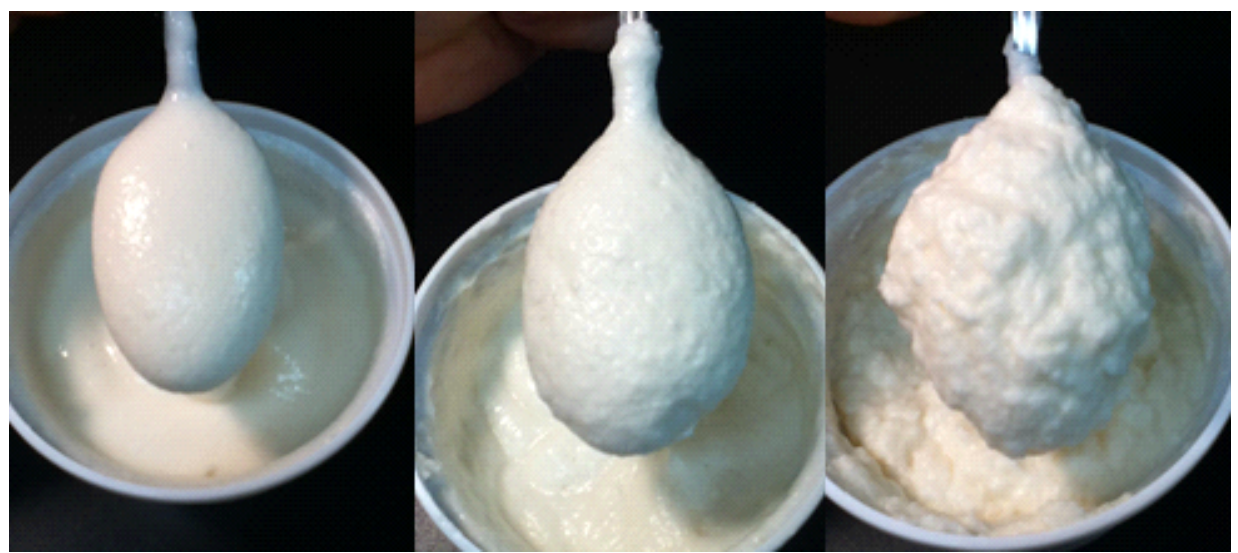

Level 1

Level 2

Level 3

Figure 2. Ordinal levels used for the classification of samples according to the presence and size of visible clusters

Level 0 could not be assigned to any of the evaluated samples. All samples presented visible clusters.

\section{Experimental design and statistical analysis}

The market reference samples were evaluated for their rheological and physicochemical properties at day 18 and 35 after their production. All measurements were carried out in triplicate. According to the data collected from these analyses, a mean reference value and a two-sided confidence interval $(\alpha=0.05)$ was established for each parameter tested. Reference confidence intervals at $P<0.05$ were used for comparisons with experimental data.

\section{Results and discussion}

\section{Dynamic rheological analyses}

In particular, the weak viscoelastic nature of yogurt gel is well established and the rheological properties of yogurt can be explained by measuring its viscous ( $\left.G^{\prime \prime}\right)$ and elastic $\left(G^{\prime}\right)$ moduli [25]. Figure 3 shows the dynamic moduli ( $G^{\prime}$ and $\left.G^{\prime \prime}\right)$ of the reference samples when applying a stress amplitude sweep test. Consistent with the data presented in Figure 3, it can be stated that Greek-style yogurt is a typical weak viscoelastic gel whose elastic properties predominate over its viscous properties over the measured range. 


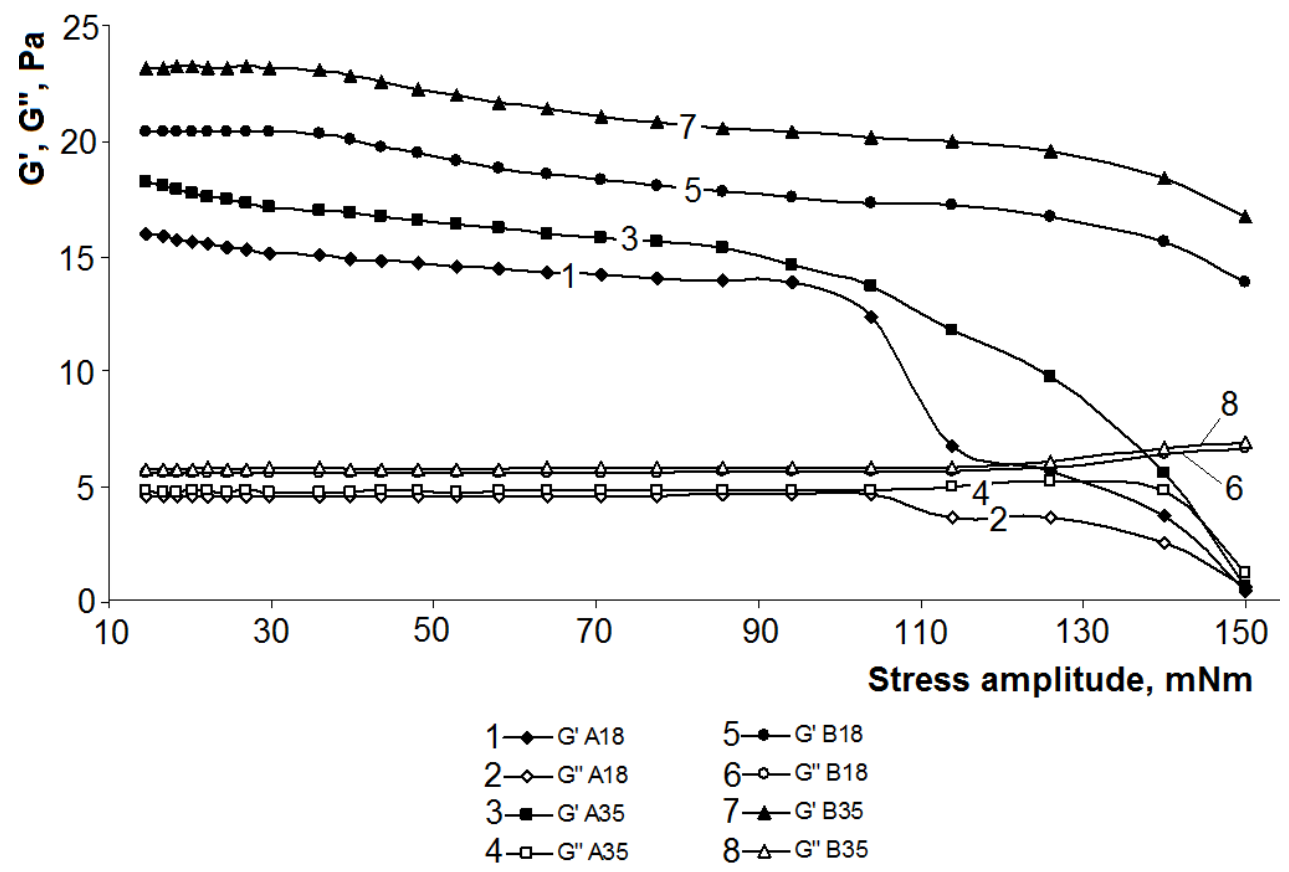

Figure 3. Storage (G') and loss (G') modulus of reference samples at days 18 and 35 after their production

Presented values are the means of triplicate measurements.

According to the previous figure, both fundamental dynamic parameters ( $G^{\prime}$ and $\left.G^{\prime \prime}\right)$ showed a stress-amplitude dependence. Also, a linear viscoelastic region was evident for all samples. A structural degradation was observed in all samples at some point during the stressamplitude range applied. These breakdown as a function of amplitude suggests that mechanical changes produced in the gels during the manufacturing process would lead to drastic rheological changes [20]. Ozer et al. [25] stated that yogurt is a metastable gel and any change in its enthalpic/entropic nature creates irreversible deformation.

Although both types of reference samples had the same protein contents (Table 1), B sample had higher $G^{\prime}$ and $G^{\prime \prime}$ moduli than A sample. As a result of more protein-protein interactions at higher protein levels, a much denser and stronger gel structure can be expected; however, the rheological properties of yogurt are not only dependent on the protein content, but are also highly dependent on total solids content and on the type of protein present in the gel matrix [29-31]. B samples had a higher total solids content than A samples (Table 1); therefore, this might be the reason that B samples presented higher dynamic moduli than A samples. Even though the spatial distribution of the protein-protein bonds over the gel network, the strength of the interaction forces between protein molecules and the structure of the protein particles themselves also defined the mechanical properties of a gel network [32, 33].

Both reference samples presented a significant increase in their $\mathrm{G}^{\prime}$ and $\mathrm{G}^{\prime \prime}$ upon storage at $5^{\circ} \mathrm{C}$. This matches the findings of Marafon et al. [34], Serra et al. [35] and Weidendorfer et al. [36], who reported an increase in $\mathrm{G}^{\prime}$ in stirred yogurts within storage. This fact suggests 
that casein gels are dynamic by nature and that further development of the gel structure occurs during storage [37]. Ozer et al. [26] affirms this point by stating that the number and/or strength of nonrelaxing and relaxing protein bonds in a protein gel matrix increases during storage. Upon storage, casein particles experience several large-scale rearrangements which result in the formation of new linkages to decrease the total free energy of the system and move to a more thermodynamically stable state $[20,35,37]$.

Figure 4 presents the loss tangent ( $\tan \delta=\mathrm{G}^{\prime \prime} / \mathrm{G}^{\prime}$ ) values of the reference samples in days 18 and 35 after their production. Although B samples had higher $G^{\prime \prime}$ and $G^{\prime}$ values than A samples, within the linear viscoelastic region, the $\tan \delta$ values of these two samples were similar.

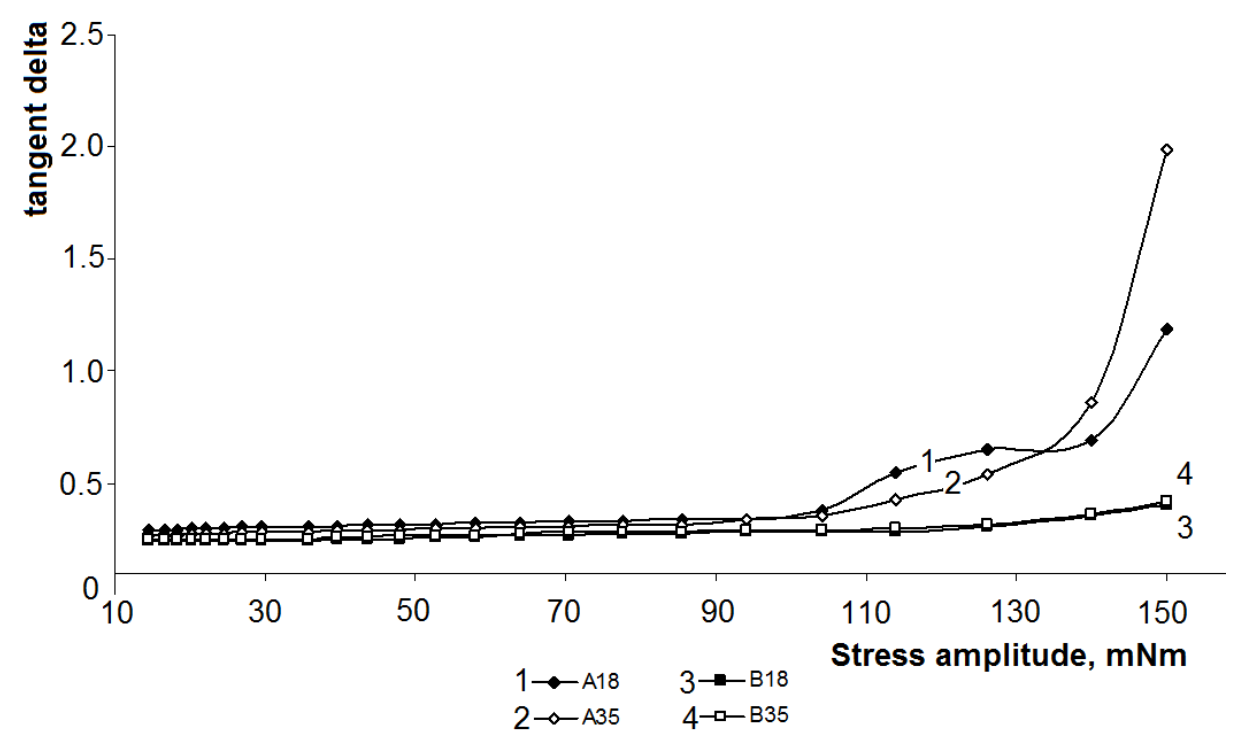

Figure 4. Loss $\operatorname{tangent}\left(\tan \delta=G^{\prime \prime} / G^{\prime}\right)$ values of reference samples at days 18 and 35 after their production

Presented values are the means of triplicate measurements.

Loss tangent values are highly dependent on the nature of bonds between the particles integrating the gel network $[25,27,38]$. Thus, it can be stated that at low amplitudes, the nature of bonds between the particles integrating both gels was similar. However, at high amplitudes, A samples presented a significant increase in their $\tan \delta$ values due to the rupture of their gel structures, which resulted in a non-proportional decrease in the number and/or strength of non-relaxing protein bonds and relaxing bonds. After the breakage point, the number and/or strength of non-relaxing bonds declined more rapidly than the number and/or strength of relaxing bonds; therefore, G' decreased more pronouncedly than G", indicating a partial breakdown of the elastic structure and a change to a relatively more viscous behavior. Due to this fact, at high amplitudes, A samples had a higher liquid-like behavior than B samples, and a significant difference in $\tan \delta$ values was observed between both samples [39, 40]. 
Even though the $\mathrm{G}^{\prime}$ and $\mathrm{G}^{\prime \prime}$ of both reference samples increased upon storage time (the number and/or strength of non-relaxing protein bonds and rapidly relaxing bonds increase with storage time), the tan $\delta$ remained almost unchanged for each sample throughout the storage period, suggesting the formation of essentially similar network structures throughout storage time [26]. This fact led to a proportional increase in $\mathrm{G}^{\prime}$ and $\mathrm{G}^{\prime \prime}$ during storage; hence, the $\tan \delta$ values $\left(\tan \delta=\mathrm{G}^{\prime \prime} / \mathrm{G}^{\prime}\right)$ for the same types of samples, after 18 and 35 days of storage, were similar. For comparative purposes, Table 2 provides the two-sided confidence interval limits $(\alpha=0.05)$ for the mean $G^{\prime}$ and $\tan \delta$ values of the reference samples at points 1,12 and 25 of the sweeping amplitude range applied. This table also presents the corresponding confidence interval limits $(\alpha=0.05)$ for the mean SWO value of the reference samples and the mean values of the ordinal measurements (WD; presence and size of clusters) that were carried out on these samples.

\section{Rheological and physicochemical values of the market reference samples}

Table 2

\begin{tabular}{|c|c|}
\hline Parameters tested & Market Reference Values \\
\hline $\mathrm{G}^{\prime}(\mathrm{Pa})[\mathrm{P} 1: 14.6 \mu \mathrm{Nm}]^{\dagger}$ & $22.358-16.226^{\mathrm{a}}$ \\
\hline $\mathrm{G}^{\prime \prime} / \mathrm{G}^{\prime}[\mathrm{P} 1: 14.6 \mu \mathrm{Nm}]^{\dagger}$ & $0.257-0.249^{a}$ \\
\hline $\mathrm{G}^{\prime}(\mathrm{Pa})[\mathrm{P} 12: 43.6 \mu \mathrm{Nm}]^{\dagger}$ & $22.418-15.374^{\mathrm{a}}$ \\
\hline $\mathrm{G}^{\prime \prime} / \mathrm{G}^{\prime}[\mathrm{P} 12: 43.6 \mu \mathrm{Nm}]^{\dagger}$ & $0.283-0.260^{\mathrm{a}}$ \\
\hline $\mathrm{G}^{\prime}(\mathrm{Pa})[\mathrm{P} 25: 150 \mu \mathrm{Nm}]^{\dagger}$ & $16.304-0.000^{\mathrm{a}}$ \\
\hline $\mathrm{G}^{\prime \prime} / \mathrm{G}^{\prime}[\mathrm{P} 25: 150 \mu \mathrm{Nm}]^{\dagger}$ & $5.324-0.040^{\mathrm{a}}$ \\
\hline $\mathrm{SWO}(\% \mathrm{~m} / \mathrm{m})^{\dagger}$ & $0.190-0.028^{\mathrm{a}}$ \\
\hline $\mathrm{WD}^{\S}$ & $0.000 \pm 0.000^{b}$ \\
\hline Presence and size of clusters ${ }^{\S}$ & $1.000 \pm 0.000^{b}$ \\
\hline
\end{tabular}

As the level of WD and the size of visible clusters were measured using ordinal scales, confidence intervals could not be determined for this type of data. Therefore, the total mean values for these two measurements were considered as reference values for comparison with experimental data.

\section{Physicochemical analyses}

Table 3 shows the physicochemical results obtained from market reference samples at days 18 and 35 after their production. Samples did not differ in levels of WD and in the size of visible clusters. All tested samples presented significant levels of SWO. Both market samples presented higher amounts of SWO as storage time increased. Due to this fact, it can be stated that, during storage, large scale rearrangements occurred in the gel network which increased the level of instability of the gel, resulting in the loss of the ability to entrap all the serum phase [28]. This observation agrees with Al-Kadamany et al. [41] who reported that the level of free whey in concentrated yogurt produced by the traditional method increases upon storage. Additionally, Salvador \& Fiszman [42] reported that the level of syneresis in whole and skimmed set types of yogurt increases with storage time. 
Physicochemical properties of market reference samples ${ }^{\sharp}$

\begin{tabular}{|l|c|c|c|}
\hline $\begin{array}{c}\text { Reference } \\
\text { samples }\end{array}$ & $\begin{array}{c}\text { Surface whey-off } \\
\mathbf{( \% )} \mathbf{m} / \mathbf{m})\end{array}$ & $\begin{array}{c}\text { Whey } \\
\text { drainage }\end{array}$ & $\begin{array}{c}\text { Size of visible } \\
\text { clusters }\end{array}$ \\
\hline A - Day 18 & $0.050 \pm 0.087$ & $0.000 \pm 0.000$ & $1.000 \pm 0.000$ \\
\hline A - Day 35 & $0.203 \pm 0.021$ & $0.000 \pm 0.000$ & $1.000 \pm 0.000$ \\
\hline B - Day 18 & $0.030 \pm 0.052$ & $0.000 \pm 0.000$ & $1.000 \pm 0.000$ \\
\hline B - Day 35 & $0.153 \pm 0.150$ & $0.000 \pm 0.000$ & $1.000 \pm 0.000$ \\
\hline Total mean value & $0.109 \pm 0.083$ & $0.000 \pm 0.000$ & $1.000 \pm 0.000$ \\
\hline
\end{tabular}

$¥$ Presented values are the means of 3 replicate trials \pm SD

Although none of the reference samples had visible WD, all of them presented small visible clusters. According to Lee \& Lucey [21], stirred yogurts are likely to have clusters of protein aggregates which are presumably created by the collisions and shearing during the mixing process involved in their production. Due to this mechanical process, the characteristic three-dimensional gel matrix of set yogurt is no longer visible in stirred products. Lee \& Lucey [40] stated that stirred yogurt is a weak gel system and although "particle size" is sometimes reported for stirred yogurt it should be recognized that there are no individual particles; rather, there are weakly associated clusters of proteins that make up the network. The stirring action associated with the production of stirred yogurts disrupts the weak protein network and creates "particles". It is important to remark that the damage done to the coagulum during the production of concentrated stirred yogurts has a major impact on the viscosity of the final products. The larger the undisturbed aggregations of casein, and the smaller the whey-filled spaces, the higher the viscosity of the final product [32].

Several researchers, such as Weidendorfer et al. [36], studied and continue to study the way to avoid or minimize visual particles in stirred yogurt. Kucukcetin [43] stated that numerous manufacturing parameters, such as high incubation temperatures, excessive whey protein to casein ratios, certain types of starter cultures and the use of excessive amounts of starter culture, are associated with textural defects of stirred yogurt, including graininess (particles) and surface roughness (irregularities in the yogurt matrix). Thus, to minimize visual clusters in the final product, it is very important to control these production parameters.

\section{Conclusions}

Protein is not the only ingredient shaping structure and rheological properties of Greek-style nonfat yoghurt. Other non-fat ingredients influence probably the structure of the protein particles and forces between protein molecules. Properties of commercial plain non-fat Greek-style yogurts change at the storage time. Samples become more solid, but with higher whey syneresis. After 35 days of storage commercial Greek-style non-fat yoghurt had good properties without visible whey drain drainage and small clusters.

\section{References}

1. Lange I., Mleko S., Tomczyńska-Mleko M., Polischuk G., Janas P., Ozimek L. (2020), Technology and factors influencing Greek-style yogurt - a Review, Ukrainian Food Journal, 9(1), pp. 7-35. 
2. Yazici F., Akgun A. (2004), Effect of some protein based fat replacers on physical, chemical, textural, and sensory properties of strained yoghurt, Journal of Food Engineering, 62(3), pp. 245-254.

3. Mihyar G. F., Yousif A. K., Yamani, M. I. (1999), Determination of benzoic and sorbic acids in labneh by high-performance liquid chromatography, Journal of Food Composition and Analysis, 12(1), pp. 53-61.

4. Yildiz F. (2009), Overview of yogurt and other fermented dairy products. In F. Yildiz (Ed.), Development and manufacture of yogurt and other functional dairy products, CRC Press.

5. Robinson R.K. (2002), Yoghurt types and manufacture. In P.F. Fox (Ed.), Encyclopedia of Dairy Sciences, Elsevier Science, Burlington.

6. Mahdian E., Tehrani M. M. (2007), Evaluation the effect of milk total solids on the relationship between growth and activity of starter cultures and quality of concentrated yoghurt, American-Eurasian Journal of Agricultural \& Environmental Science, 2(5), pp. 587-592.

7. Nsabimana, C., Jiang, B., Kossah, R. (2005), Manufacturing, properties and shelf life of labneh: A review, International Journal of Dairy Technology, 58(3), pp. 129-137.

8. Salji J. (1991), Concentrated yogurt: a challenge to our food industry, Food Science and Technology Today, 5, pp. 18-19.

9. United States Department of Agriculture (USDA) (2018), Profiling food consumption in America. In USDA (Ed.), Agriculture Fact Book 2018.

10. Chandan R. C. (2008), Dairy industry: production and consumption trends. In R.C. Chandan, A. Kilara, \& N.P. Shah (Eds.), Dairy processing \& quality assurance, Wiley-Blackwell.

11. Kneifel W. (1993), Recombined and filled milks. In R. Macrae, R.K. Robinson, \& M.J. Sadler (Eds.), Encyclopedia of Food Science, Food Technology and Nutrition, London.

12. Ozer B. H, Robinson R. K. (1999), The behaviour of starter cultures in concentrated yoghurt (labneh) produced by different techniques, Lebensmittel-wissenschaft Und-Technologie, 32(7), pp. 391-395.

13. Tamime A. Y., Robinson, R. K. (1999), Traditional and recent developments in yoghurt production and related products. In A. Y. Tamime, \& R.K. Robinson (Eds.), Yoghurt: Science and technology $2^{\text {nd }}$ Edition, CRC Press.

14. Tamime A. Y., Davies G., Chehade A. S., Mahdi H. A. (1991), The effect of processing temperatures on the quality of labneh made by ultrafiltration, International Journal of Dairy Technology, 44(4), pp. 99-103.

15. Abu-Jdayil B., Jumah R. Y., Shaker R. R. (2002), Rheological properties of a concentrated fermented product, labneh, produced from bovine milk: effect of production method, International Journal of Food Properties, 5(3), pp. 667-680.

16. Tamime A. Y. (2003), Yogurt-based products. In B. Caballero, L. Trugo, \& P. Finglas (Eds.), Encyclopedia of Food Science and Nutrition $2^{\text {nd }}$ Edition, Academic Press, London.

17. Tamime A. Y., Robinson R. K. (2007), Traditional and recent developments in yoghurt production and related products, In A. Y. Tamime, \& R.K. Robinson (Eds.), Yoghurt: Science and technology $3^{\text {rd }}$ Edition (pp. 348-367), CRC Press, Boca Raton, FL.

18. Gould B. W., Cornick J., Cox, T. (1994), Consumer demand for new reduced-fat foods: an analysis of cheese expenditures, Canadian Journal of Agricultural Economics, 42(3), pp. 367-380.

19. Abu-Jdayil, B., Shaker, R. R., Jumah, R. Y. (2000), Rheological behavior of concentrated yogurt (labneh), International Journal of Food Properties, 3(2), pp. 207-216.

20. Lucey J. A. (2002), Formation and physical properties of milk protein gels, Journal of Dairy Science, 85(2), pp. 281-294.

21. Lee W. J., Lucey J. A. (2006), Impact of gelation conditions and structural breakdown on the physical and sensory properties of stirred yogurts, Journal of Dairy Science, 89(7), pp. 2374-2385. 
22. Skriver A., Holstborg J., Qvist, K. B. (1999), Relation between sensory texture analysis and rheological properties of stirred yogurt, Journal of Dairy Research, 66(4), pp. 609-618.

23. Richardson R. K., Morris E. R., Ross-Murphy S. B., Taylor L.J., Dea I. C. M. (1989), Characterization of the perceived texture of thickened systems by dynamic viscosity measurements, Food Hydrocolloids, 3(3), pp. 175-191.

24. Stanley N. L., Taylor L. J. (1993), Rheological basis of oral characteristics of fluid and semisolid foods: a review, Acta Psychologica, 84(1), pp. 79-92.

25. Ozer B. H., Robinson, R. K., Grandison, A. S., Bell, A. E. (1997), Comparison of techniques for measuring the rheological properties of labneh (concentrated yogurt), International Journal of Dairy Technology, 50(4), pp. 129-133.

26. Ozer B. H., Robinson R. K., Grandison A. S., Bell A. E. (1998), Gelation properties of milk concentrated by different techniques, International Dairy Journal, 8(9), pp. 793-799.

27. Ozer B. H., Stenning R. A., Grandison A. S., Robinson R. K. (1999), Rheology and microstructure of labneh (concentrated yogurt), Journal of Dairy Science Champaign Illinois, 82(4), pp. 682-689.

28. Lucey J. A., Munro P. A., Singh H. (1998), Whey separation in acid skim milk gels made with glucono- $\delta$-lactone: effects of heat treatment and gelation temperature, Journal of Texture Studies, 29(4), pp. 413-426.

29. Oliveira M. N., Sodini I., Remeuf F., Corrieu G. (2001), Effect of milk supplementation and culture composition on acidification, textural properties and microbiological stability of fermented milks containing probiotic bacteria, International Dairy Journal, 11(11), pp. 935 942.

30. Jumah R. Y., Shaker R. R., Abu-Jdayil B. (2001), Effect of milk source on the rheological properties of yogurt during the gelation process, International Journal of Dairy Technology, 54(3), pp. 89-93.

31. Barreto Penna A. L., Converti A., Nogueira de Oliveira, M. (2006), Simultaneous effects of total solids content, milk base, heat treatment temperature and sample temperature on the rheological properties of plain stirred yogurt, Food Technology and Biotechnology, 44(4), pp. 515-518.

32. Ozer B. H, Stenning R.A., Grandison A.S., Robinson R.K. (1999). Effect of protein concentration on the properties and structure of concentrated yogurts, International Journal of Dairy Technology, 52(4), pp. 135-138.

33. Bremer L. G. B., Bijsterbosch B. H., Schrijvers R., van Vliet T., Walstra P. (1990), On the fractal nature of the structure of acid casein gels, Colloids and Surfaces, 51, pp. 159-170.

34. Marafon A. P., Sumi A., Granato D., Nogueira O. M., Alcantara M. R., Tamime A. Y. (2011), Effects of partially replacing skimmed milk powder with dairy ingredients on rheology, sensory profiling, and microstructure of probiotic stirred-type yogurt during cold storage, Journal of Dairy Science, 94(11), pp. 5330-5340.

35. Serra M., Trujillo A. J., Guamis B., Ferragut V. (2009), Evaluation of physical properties during storage of set and stirred yogurts made from ultra-high pressure homogenizationtreated milk, Food Hydrocolloids, 23(1), pp. 82-91.

36. Weidendorfer K., Bienias A., Hinrichs J. (2008), Investigation of the effects of mechanical post-processing with a colloid mill on the texture properties of stirred yogurt, International Journal of Dairy Technology, 61(4), pp. 379-384.

37. van Vliet T., Lucey J. A., Grolle K., Walstra P. (1997), Rearrangements in acid-induced casein gels during and after gel formation. In E. Dickinson, \& Bergenstahl (Eds.), Food colloids. Protein, lipids and polysaccharides, Royal Society of Chemistry, Cambridge.

38. Ozer B. H., Bell A. E., Grandison A. S., Robinson R. K. (1998). Rheological properties of concentrated yoghurt (labneh), Journal of Texture Studies, 29(1), pp. 67-80. 
39. Biliaderis C. G. (2009), Structural transitions and related physical properties of starch. In J. BeMiller, \& R. Whistler (Eds.), Starch: Chemistry and technology, Academic Press, Burlington, MA.

40. Lee W. J., Lucey J. A. (2010), Formation and physical properties of yogurt, Asianaustralasian Journal of Animal Sciences, 23(9), pp. 1127-1136.

41. Al-Kadamany E., Toufeili I., Khattar M., Abou-Jawdeh Y., Harakeh S., Haddad T. (2002), Determination of shelf life of concentrated yogurt (labneh) produced by in-bag straining of set yogurt using hazard analysis, Journal of Dairy Science, 85(5), pp. 1023-1030.

42. Salvador A., Fiszman S. M. (2004), Textural and sensory characteristics of whole and skimmed flavored set-type yogurt during long storage, Journal of Dairy Science, 87(12), pp. 4033-4041.

43. Kucukcetin A. (2008), Effect of heat treatment and casein to whey protein ratio of skim milk on graininess and roughness of stirred yoghurt, Food Research International, 41(2), pp. $165-171$. 